\title{
The interaction between miR-148a and DNMT1 suppresses cell migration and invasion by reactivating tumor suppressor genes in pancreatic cancer
}

\author{
LE HONG $^{1 *}$, GEN SUN $^{1 *}$, LONG PENG $^{2}$, YI TU $^{3}$, ZHEN WAN $^{1}$, \\ HAIWEI XIONG ${ }^{1}$, YONG LI ${ }^{1}$ and WEIDONG XIAO ${ }^{1}$ \\ ${ }^{1}$ Department of General Surgery, The First Affiliated Hospital of Nanchang University; \\ ${ }^{2}$ Department of General Surgery, The Second Affiliated Hospital of Nanchang University; \\ ${ }^{3}$ Department of Pathology,The First Affiliated Hospital of Nanchang University, \\ Nanchang, Jiangxi 330006, P.R. China
}

Received May 13,2018; Accepted September 10, 2018

DOI: $10.3892 /$ or.2018.6700

\begin{abstract}
DNA methylation is an epigenetic mechanism that cells use to control gene expression, which serves an important role in tumorigenesis. DNA methyltransferase 1 (DNMT1) is responsible for the maintenance of the pattern of DNA methylation. Overexpression of DNMT1 is observed in numerous malignant tumors, including pancreatic cancer, and results in silencing of several key tumor suppressor genes (TSGs). Recent studies have suggested that microRNAs (miRNAs/miRs) contribute to the regulation of DNMT1 expression, and promoter hypermethylation caused by DNMT1 overexpression is associated with the dysfunction of some miRNAs. The present study aimed to reveal the interaction between miR-148a and DNMT1, and its effects on cell proliferation, migration and invasion of pancreatic cancer cells. Initially, the expression levels of DNMT1 and miR-148a were detected in pancreatic cancer tissues and AsPC-1 cells by reverse transcription-quantitative polymerase chain reaction (PCR). Secondly, the regulatory effects of DNMT1 on miR-148a were evaluated using methylation-specific PCR. Furthermore, bioinformatics analysis and dual luciferase reporter assay were used to verify the target relationship between miR-148a and DNMT1. Finally, in vitro rescue experiments were conducted to evaluate the effects of miR-148a on the expression of TSGs and the malignant phenotype in AsPC-1 cells. The results demonstrated that DNMT1 was aberrantly upregulated in
\end{abstract}

Correspondence to: Dr Weidong Xiao, Department of General Surgery, The First Affiliated Hospital of Nanchang University, 17 Yongwaizhengjie, Nanchang, Jiangxi 330006, P.R. China E-mail: frankxwd@126.com

*Contributed equally

Key words: pancreatic cancer, microRNA-148a, DNA methyltransferase 1 , tumor suppressor gene, cell proliferation pancreatic cancer, and was responsible for hypermethylation of the miR-148a promoter. Furthermore, DNMT1 was revealed as a direct target of miR-148a by dual luciferase reporter assay, and restoration of miR-148a could reactivate TSGs, such as p16, preproenkephalin and Ras association domain family member 1 by targeting DNMT1 in the AsPC-1 pancreatic cancer cell line. These results indicated that an interaction exists between miR-148a and DNMT1 in pancreatic cancer. Notably, miR-148a overexpression significantly inhibited cell proliferation, migration and invasion in AsPC-1 cells. Therefore, miR-148a may serve as a novel therapeutic target for the treatment of pancreatic cancer.

\section{Introduction}

Pancreatic cancer is widely recognized as one of the most aggressive malignancies of the digestive system, which is associated with a poor prognosis. The American Cancer Society estimates that 55,440 Americans will be diagnosed with pancreatic cancer in 2018, and that 44,330 will succumb to the disease (1). It is currently listed as the fourth leading cause of cancer-associated mortality and is predicted to become the second by 2030 in the USA (2). In China, 90,100 new cases of pancreatic cancer and 79,400 cases of pancreatic cancer-associated mortality were estimated to occur in 2015 (3). Despite considerable advances in surgical and oncological treatment in recent years, the overall 5-year survival rate for pancreatic cancer is still $\sim 8 \%$. One of the main factors contributing to the poor prognosis of pancreatic cancer is late diagnosis, when it has already metastasized to distant organ sites and is unresectable. In addition, there remains a lack of an effective therapy for metastatic pancreatic cancer; therefore, the current status of diagnosis and treatment of pancreatic cancer is challenging. There is an urgent need to elucidate the underlying mechanisms of pancreatic cancer, which regulate its pathogenesis and progression, and provide useful information for the clinical management of pancreatic cancer.

MicroRNAs (miRNAs/miRs) are non-coding RNA molecules, 18-22 bases in length, which post-transcriptionally 
regulate gene expression through binding to a sequence in the 3'-untranslated region (3'UTR), which has partial or full complementarity. It has been indicated that miRNAs serve an important role in regulating cancer-associated processes, such as proliferation, cell cycle progression, apoptosis, angiogenesis, invasion and metastasis (4). According to the distinct cellular function of their targets in different tumors, miRNAs may function as oncogenes or tumor suppressors in the development of cancer. miR-148a is a member of the miR-148/152 family, which is located at chromosome $7 \mathrm{p} 15.2$. In previous studies, miR-148a has been identified as a tumor suppressor miRNA that is downregulated in various types of cancer, including breast cancer (5), gastrointestinal cancers $(6,7)$, cholangiocarcinoma (8) and hepatocellular carcinoma (9). miR-148a is also downregulated in pancreatic cancer tissues and several pancreatic cell lines $(10,11)$. In addition, DNA methyltransferase 1 (DNMT1) (12), cholecystokinin B receptor (13), B-cell lymphoma 2 (13), cell division cycle 25B (14) and erb-b2 receptor tyrosine kinase 3 (15) have been identified as target genes of miR-148a.

DNA methylation is one of the epigenetic mechanisms affecting cell fate via the regulation of gene expression. Aberrant hypermethylation of $\mathrm{CpG}$ sites is often involved in silencing of tumor suppressor genes (TSGs). Furthermore, previous studies have identified $\mathrm{CpG}$ island methylationassociated silencing of miRNAs with tumor suppressor features in human cancer $(16,17)$. DNMT1 is responsible for the maintenance of the pattern of DNA methylation. Previous reports have demonstrated that DNMT1 is overexpressed in pancreatic cancer tissues and cell lines; furthermore, increased DNMT1 expression is markedly correlated with poor prognosis $(18,19)$. DNMT1 has also been verified as a target for miR-148a in gastric (20) and breast cancer (5), and hepatocellular carcinoma (21) and pancreatic cancer (12). Furthermore, hypermethylation of the miR-148a promoter is associated with DNMT1 overexpression in pancreatic cancer (12). Therefore, the interaction between miR-148a and DNMT1 may regulate the expression of TSGs in pancreatic cancer.

Our previous study demonstrated that miR-148a is markedly downregulated in human pancreatic ductal adenocarcinoma (PDAC) cell lines and tissues. In addition, the downregulation of miR-148a is associated with poor prognosis and epithelial-mesenchymal transition (EMT). Conversely, restoration of miR-148a suppresses EMT and invasion of pancreatic cancer cells by targeting Wnt10b and inhibiting the Wnt/ $\beta$-catenin signaling pathway (22). The present study aimed to reveal the interaction between miR-148a and DNMT1, and its effects on TSG expression, cell proliferation, migration and invasion of pancreatic cancer cells. The findings may provide novel insights into the upstream and downstream regulatory mechanisms of miR-148a in pancreatic cancer, and may identify a potential target for the future treatment of pancreatic cancer.

\section{Materials and methods}

Tissue samples. A total of 30 paired PDAC and adjacent non-tumorous tissues (ANT) were obtained from patients with PDAC who underwent surgery between January 2013 and December 2015 at The First Affiliated Hospital of Nanchang University (Nanchang, China). None of the patients received radiotherapy or chemotherapy prior to surgery. The samples were snap-frozen and stored at $-80^{\circ} \mathrm{C}$ until analysis. Written informed consent was obtained from all participants prior to recruitment. The present study was approved by the Ethics Committee of The First Affiliated Hospital of Nanchang University.

Cell lines and cell culture. The normal human pancreatic ductal epithelial cell line HPDE and the pancreatic cancer cell line AsPC-1 were obtained from the Type Culture Collection of the Chinese Academy of Sciences (Shanghai, China). AsPC-1 cells were routinely cultured in Dulbecco's modified Eagle's medium (DMEM; Gibco; Thermo Fisher Scientific, Inc., Waltham, MA, USA) supplemented with $10 \%$ fetal bovine serum (FBS; Gibco; Thermo Fisher Scientific, Inc.), penicillin $(100 \mathrm{U} / \mathrm{ml})$ and streptomycin $(100 \mu \mathrm{g} / \mathrm{ml})$ in an incubator containing $95 \%$ air and $5 \% \mathrm{CO}_{2}$.

5-Aza-2'-deoxycytidine (5-Aza-CdR) treatment. AsPC-1 cells were seeded in 6 -well plates $\left(5 \times 10^{5}\right.$ cells/well), and were treated with $5 \mu \mathrm{M}$ 5-Aza-CdR (Sigma-Aldrich; Merck KGaA, Darmstadt, Germany) for $72 \mathrm{~h}$; 5-Aza-CdR containing medium was replaced every $24 \mathrm{~h}$. Exponentially growing cells were used for subsequent assays.

RNA interference. To silence DNMT1 expression, DNMT1small interfering RNA (siRNA) (Ambion; Thermo Fisher Scientific, Inc.) was transfected into AsPC-1 cells. The DNMT1 siRNA sequences were as follows: Sense, 5'-AGA UGACGGAUGCCUAGAGUU-3'; antisense, 5'-CUCUAG GCAUCCGUCAUCUUU-3'. Negative control (NC) siRNA was also purchased from Ambion; Thermo Fisher Scientific, Inc. (cat. no. 4390843). The final siRNA concentration was $10 \mathrm{nM}$. Cells were plated at $2 \times 10^{5}$ cells/well in a 6 -well plate overnight, and were then transfected with siRNA at room temperature using Lipofectamine ${ }^{\circledR} 2000$ (Invitrogen; Thermo Fisher Scientific, Inc.), according to the manufacturer's protocol. Cells were collected for RNA and protein extraction or for further assays $48 \mathrm{~h}$ post-transfection.

Synthetic miRNA transfection. AsPC-1 cells were seeded at $2 \times 10^{5}$ cells/well into a 12 -well plate, and were incubated overnight, after which, the cells were transfected with $100 \mathrm{nM}$ miR-148a mimics (cat. no. 4464066) or mimics-NC (cat. no. 4464058; Ambion; Thermo Fisher Scientific, Inc.) for $48 \mathrm{~h}$ at room temperature using Lipofectamine ${ }^{\circledR} 2000$ (Invitrogen; Thermo Fisher Scientific, Inc.), according to the manufacturer's protocol. Cells transfected with Lipofectamine ${ }^{\circledR}$ only were considered a blank control. Cells were collected for RNA and protein extraction, or for further assays, $48 \mathrm{~h}$ post-transfection.

$R N A$ isolation and reverse transcription-quantitative polymerase chain reaction ( $R T-q P C R)$. Total RNA was isolated from AsPC-1 cells using TRIzol ${ }^{\circledR}$ reagent (Invitrogen; Thermo Fisher Scientific, Inc.) and was quantified using a NanoDrop spectrophotometer (NanoDrop; Thermo Fisher Scientific, Inc., Wilmington, DE, USA). Total RNA ( $2 \mu \mathrm{g})$ was used as a template for synthesizing cDNA using the M-MLV Reverse Transcriptase kit (Takara Bio, Inc., Otsu, Japan), according to 
the manufacturer's protocol. qPCR was performed using the Applied Biosystems 7500 Fast Real-Time PCR system with the SYBR-Green PCR kit (Applied Biosystems; Thermo Fisher Scientific, Inc., Waltham, MA, USA) to detect DNMT1 and miR-148a expression. The thermocycling conditions were as follows: $94^{\circ} \mathrm{C}$ for $4 \mathrm{~min}$, followed by 40 cycles at $94^{\circ} \mathrm{C}$ for $30 \mathrm{sec}, 50^{\circ} \mathrm{C}$ for $30 \mathrm{sec}$ and $72^{\circ} \mathrm{C}$ for $40 \mathrm{sec}$, followed by final extension at $72^{\circ} \mathrm{C}$ for $5 \mathrm{~min}$. $\beta$-actin and human U6 RNA served as internal control genes, respectively. Quantification cycle $(\mathrm{Cq})$ values were used to quantify the expression levels of each gene, and mRNA or miRNA levels were calculated according to the $2^{-\Delta \Delta C q}$ method (23). The primer sequences are shown in Table I:

Protein extraction and western blot analysis. Total proteins were extracted with radioimmunoprecipitation assay lysis buffer (Santa Cruz Biotechnology, Inc., Dallas, TX, USA) and the protein concentration of each sample was determined using the Bicinchoninic Acid Protein Assay kit (Thermo Fisher Scientific, Inc.). Equal amounts of protein (50 $\mu \mathrm{g} / \mathrm{lane})$ were subjected to $10 \%$ SDS-PAGE, and were then transferred to nitrocellulose membranes (EMD Millipore, Billerica, MA, USA). After blocking with 5\% skimmed milk in Tris-buffered saline-Tween (TBST; $20 \mathrm{mM}$ Tris- $\mathrm{HCl}, 150 \mathrm{Mm} \mathrm{NaCl}, 0.1 \%$ Tween-20; $\mathrm{pH}$ 7.6) for $5 \mathrm{~h}$ at room temperature, the membranes were incubated with primary antibodies overnight at $4^{\circ} \mathrm{C}$. After washing with TBST, membranes were incubated with the appropriate horseradish peroxidase-conjugated secondary antibody (1:2,000, cat. no. ab205718; Abcam, Cambridge, MA, USA) for $2 \mathrm{~h}$ at room temperature. Finally, the proteins were visualized using enhanced chemiluminescence reagents (EMD Millipore). Band intensity was semi-quantified using Quantity One image analysis software version 4.62 (Bio-Rad Laboratories, Inc., Hercules, CA, USA). The primary antibodies used were as follows: DNMT1 (1:500, cat. no. ab188453; Abcam), p16 (1:200, cat. no. ab51243; Abcam), preproenkephalin (ppENK; 1:100, cat. no. ab98128; Abcam) and Ras association domain family member 1 (RASSF1A; 1:200, cat. no. ab97749; Abcam). $\beta$-tubulin (1:500, cat. no. ab151318; Abcam) was used as an internal loading control.

DNA extraction, methylation-specific PCR (MSP) and bisulfite sequencing PCR (BSP). Genomic DNA of tissues and cells was extracted using QIAamp DNA Mini kit (Qiagen GmbH, Hilden, German) and quantified using the Quantifiler Human DNA Quantification kit (Applied Biosystems; Thermo Fisher Scientific, Inc.). Aliquots of genomic DNA were treated with sodium bisulfite using the EZ DNA Methylation-Gold ${ }^{\mathrm{TM}}$ kit (Zymo Research Corp., Irvine, CA, USA), according to the manufacturer's protocol. The methylation status of miR-148a and three TGSs (p16, ppENK and RASSF1A) was analyzed by MSP. The methylated and unmethylated primers are listed in Table I. Briefly, PCR was conducted in a $50 \mu \mathrm{l}$ volume containing $10 \mathrm{pmol} / \mu \mathrm{l}$ each primer $(1 \mu \mathrm{l}), 10 \mathrm{ng} / \mu \mathrm{l}$ bisulfte-modifed DNA (5 $\mu \mathrm{l}), 10 \mathrm{X}$ PCR buffer $(5 \mu \mathrm{l}), 10 \mathrm{nM}$ dNTPs $(1 \mu \mathrm{l}), 5 \mathrm{U} / \mu \mathrm{l}$ Taq DNA polymerase (0.5 $\mu \mathrm{l}$; Thermo Fisher Scientific, Inc.), $25 \mathrm{mM} \mathrm{MgCl}_{2}(5 \mu \mathrm{l})$ and $\mathrm{ddH}_{2} \mathrm{O}(31.5 \mu \mathrm{l})$. Amplification was performed using a thermocycler under the following conditions: $95^{\circ} \mathrm{C}$ for $5 \mathrm{~min}$, followed by 35 cycles at $95^{\circ} \mathrm{C}$ for $30 \mathrm{sec}$,
Table I. Primer sequences for reverse transcription-quantitative PCR, BSP and methylation-specific PCR.

\begin{tabular}{|c|c|}
\hline Gene & Sequence $\left(5^{\prime}-3^{\prime}\right)$ \\
\hline DNMT1 & $\begin{array}{l}\text { F: CGTGACATTAAGGAGAAGCTG } \\
\text { R: CTAGAAGCATTTGCGGTGGAC }\end{array}$ \\
\hline$\beta$-actin & $\begin{array}{l}\text { F: AACCTTCACCTAGCCCCAG } \\
\text { R: CTCATCCGATTTGGCTCTTCA }\end{array}$ \\
\hline $\operatorname{miR}-148 \mathrm{a}$ & $\begin{array}{l}\text { F: TGCGGTCAGTGCACTACAGAAC } \\
\text { R: CCAGTGCAGGGTCCGAGGT }\end{array}$ \\
\hline U6 & $\begin{array}{l}\text { F: CTCGCTTCGGCAGCACA } \\
\text { R: AACGCTTCACGAATTTGCGT }\end{array}$ \\
\hline miR-148a BSP & $\begin{array}{l}\text { F: ATAGGTAGTTTGGTAGAGGTTGGTC } \\
\text { R: TATCAAATCAACAAATTCCCTCC }\end{array}$ \\
\hline miR-148a-M & $\begin{array}{l}\text { F: TAGGGGAGGTTTCGTAAAGC } \\
\text { R: CACGAAAACGAATATTCGAAA }\end{array}$ \\
\hline miR-148a-U & $\begin{array}{l}\text { F: TTTTAGGGGAGGTTTTGTAAAGT } \\
\text { R: ACACAAAAACAAATATTCAAAACT }\end{array}$ \\
\hline RASSF1A-M & $\begin{array}{l}\text { F: GTGTTAACGCGTTGCGTATC } \\
\text { R: AACCCCGCGAACTAAAAACGA }\end{array}$ \\
\hline RASSF1A-U & $\begin{array}{l}\text { F: TTTGGTTGGAGTGTGTTAATGTG } \\
\text { R: CAAACCCCACAAACTAAAAACAA }\end{array}$ \\
\hline p16-M & $\begin{array}{l}\text { F: TTATTAGAGGGTGGGGCGGATCGC } \\
\text { R: GACCCCGAACCGCGACCGTAA }\end{array}$ \\
\hline p16-U & $\begin{array}{l}\text { F: TTATTAGAGGGTGGGGTGGATTGT } \\
\text { R: CAACCCCAAACCACAACCATAA }\end{array}$ \\
\hline ppENK-M & $\begin{array}{l}\text { F: TGTGGGGAGTTATCGAGC } \\
\text { R: GCCTTCGCGAAAAAAATCG }\end{array}$ \\
\hline ppENK-U & $\begin{array}{l}\text { F: TTGTGTGGGGAGTTATTGAGT } \\
\text { R: CACCTTCACAAAAAAAATCAATC }\end{array}$ \\
\hline
\end{tabular}

BSP, bisulfite sequencing PCR; DNMT1, DNA methyltransferase 1; M, methylated; miR-148, microRNA-148; PCR, polymerase chain reaction; ppENK, preproenkephalin; RASSF1A, Ras association domain family member $1 ; \mathrm{U}$, unmethylated.

$60^{\circ} \mathrm{C}$ for $60 \mathrm{sec}$ and $72^{\circ} \mathrm{C}$ for $30 \mathrm{sec}$, followed by an extension at $72^{\circ} \mathrm{C}$ for $7 \mathrm{~min}$. PCR products underwent $3 \%$ agarose gel electrophoresis containing ethidium bromide (Thermo Fisher Scientific, Inc.) and were then visualized by ultraviolet illumination. Furthermore, the methylation level of the miR-148a promoter in AsPC-1 cells treated with 5-Aza-CdR or transfected with DNMT1-siRNA was analyzed by BSP. The BSP primer was designed by Methprimer (http://www.urogene. org/methprimer/), according to the sequence of the miR-148a promoter (2 kb, NC_000007.14: c25951986-25949987), and the sequence is listed in Table I. The product size was $246 \mathrm{bp}$ with 29 CpGs. PCR amplification was performed according to the protocol of MSP. Subsequently, the amplified PCR products were purified and cloned into the pMD19-T vector (Takara Bio, Inc.); five clones of each cell were sequenced using Sanger sequencing methods (24) by Sangon Biotech Co., Ltd. (Shanghai, China). The percentage of methylation was 
calculated comprehensively and comparatively using $\mathrm{CpG}$ viewer, QUMA and Biq-analyzer $(25,26)$.

Dual luciferase reporter assay. A dual luciferase reporter assay was performed as previously described (22). The 3'UTR mRNA sequence of the DNMT1 gene containing the miR-148a binding site was amplified by PCR, in a total volume of $25 \mu \mathrm{l}$ containing $100 \mathrm{ng}$ human genomic DNA, and cloned into the pmirGLO vector (Promega Corporation, Madison, WI, USA) [DNMT1 3'UTR-wild type (wt)]. The human genomic DNA was extracted from the peripheral blood of healthy volunteers after obtaining written informed consent. Mutant DNMT1 3'UTR was generated using the overlap-extension PCR method (27) and was cloned into the pmirGLO vector [DNMT1 3'UTR-mutant (mut)]. Subsequently, the AsPC-1 cells $\left(1 \times 10^{5}\right)$ were seeded in a 48 -well plate and co-transfected with DNMT1 3'UTR-wt or DNMT1 3'UTR-mut vector $(100 \mathrm{ng})$ with miR-148a mimics or mimics-NC $(100 \mathrm{nM})$ using Lipofectamine ${ }^{\circledR} 2000$ at room temperature. Luciferase activity was detected using the Dual-Luciferase Reporter Assay system (Promega Corporation) 48 h post-transfection; the relative luciferase activity was calculated as a ratio of Firefly luciferase activity versus Renilla luciferase activity. The experiments were performed independently in triplicate.

Cell proliferation analysis. Cell proliferation was detected by MTT assay (Sigma-Aldrich; Merck KGaA). Briefly, AsPC-1 cells $\left(5 \times 10^{3}\right.$ cells/well in 96 -well plates) were transfected with Lipofectamine ${ }^{\circledR}$ as a blank control, mimics-NC or miR-148a mimics. After 24, 48, 72, 96 and $120 \mathrm{~h}$, cells were incubated with MTT $(5 \mathrm{mg} / \mathrm{ml})$ for $4 \mathrm{~h}$ at $37^{\circ} \mathrm{C}$, the supernatants were discarded and the insoluble formazan was dissolved in dimethyl sulfoxide. A microplate reader (Bio-Rad Laboratories, Inc.) was used to determine the optical density (OD) at $490 \mathrm{~nm}$. Inhibition rate $(\%)=($ OD 490 value of blank - OD 490 value of miR-148a mimics)/(OD 490 value of blank) x 100\%. All experiments were repeated three times, and the average results were calculated.

Cell migration and invasion assays. The migratory and invasive abilities of AsPC-1 cells were examined using a Transwell chamber (Corning Incorporated, Corning, NY, USA). Transwell filters coated with Matrigel were used for the tumor cell invasion assay, whereas Transwell filters without Matrigel were used for the migration assay. Briefly, $5 \times 10^{5}$ AsPC-1 cells in serum-free DMEM were plated in the upper chamber, and DMEM containing $10 \%$ FBS was added to the bottom chamber. After $24 \mathrm{~h}$ at $37^{\circ} \mathrm{C}$, cells that remained in the upper chamber were carefully removed using cotton wool. The cells that had invaded or migrated to the lower surface of the membrane and the bottom chambers were fixed with methanol for $30 \mathrm{~min}$, and stained with $0.1 \%$ crystal violet for $20 \mathrm{~min}$ at room temperature. Subsequently, the number of stained cells was counted and observed under an inverted light microscope. Five fields were randomly selected and the number of cells was expressed as the mean. The experiment was repeated three times.

Statistical analysis. Statistical analyses were performed using SPSS 22.0 software (IBM Corp., Armonk, NY, USA).
Measurement data were expressed as the means \pm standard deviation of three replicate experiments. Comparative data between the groups were assessed using a two-tailed Student's t-test, and comparisons among multiple groups were performed using one-way analysis of variance followed by the least significant difference post hoc test. Spearman's correlation test was used for correlation analyses. $\mathrm{P}<0.05$ was considered to indicate a statistically significant difference.

\section{Results}

Overexpression of DNMT1 is responsible for hypermethylation of the miR-148a gene promoter. The expression levels of miR-148a were significantly decreased in PDAC specimens compared with in ANT specimens (Fig. 1A), whereas the expression of DNMT1 was significantly increased in PDAC specimens (Fig. 1B). Furthermore, the expression of miR-148a was negatively correlated with DNMT1 expression ( $\mathrm{r}=-0.7261, \mathrm{P}<0.01$; Fig. 1C). The expression levels of DNMT1 were markedly higher in AsPC-1 cells than in HPDE cells, whereas the expression levels of miR-148a were reduced (Fig. 1D and E). To verify the hypotheses that overexpression of DNMT1 is responsible for the downregulation of miR-148a in pancreatic cancer, the present study assessed the methylation status of the miR-148a promoter by MSP in PDAC tissues and AsPC-1 cells. The results indicated that the positive rate of miR-148a methylation was significantly higher in PDAC tissues than in ANT tissues (76.7 vs. 16.7\%, $\mathrm{P}<0.01$; Fig. 2A). In addition, the methylation status of the miR-148a gene promoter was positive in AsPC-1 cells, whereas it was negative in HPDE cells (Fig. 2B). After 5-Aza-CdR treatment or DNMT1-siRNA transfection, the expression of miR-148a was significantly increased alongside downregulation of DNMT1, and the miR-148a promoter was unmethylated in AsPC-1 cells (Fig. 2C and D). Furthermore, the methylated $\mathrm{CpG}$ sites of the miR-148a promoter were significantly decreased in AsPC-1 cells following 5-Aza-CdR treatment or DNMT1-siRNA transfection $(\mathrm{P}<0.01$ Fig. 2E). These results suggested that hypermethylation of the miR-148a promoter suppressed its expression, and overexpression of DNMT1 may be responsible for hypermethylation of the miR-148a promoter in pancreatic cancer.

Restoration of miR-148a expression suppresses DNMT1 expression in vitro. To investigate the effects of miR-148a on the regulation of DNMT1 expression, AsPC-1 cells in the control groups were transfected with Lipofectamine ${ }^{\circledR}$ (blank) or mimics-NC, whereas cells in the experimental group were transfected with miR-148a mimics. As shown in Fig. 3A, miR-148a expression was significantly higher following miR-148a mimics transfection. To further investigate a miRNA-dependent mechanism of DNMT1 regulation, the protein expression levels of DNMT1 were detected by western blot analysis following transfection with miR-148a mimics. As expected, DNMT1 expression was significantly decreased in AsPC-1 cells transfected with miR-148a mimics (Fig. 3B).

miR-148a directly targets DNMT1 3'UTR. The present study revealed that DNMT1 expression was significantly inhibited by miR-148a in AsPC-1 cells. In addition, DNMT1 was identified 
A
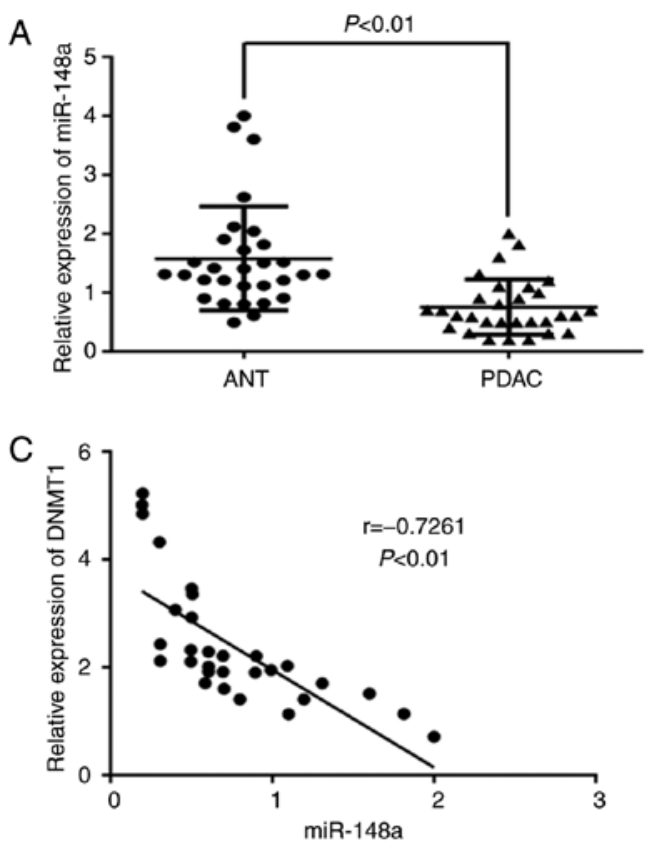

B

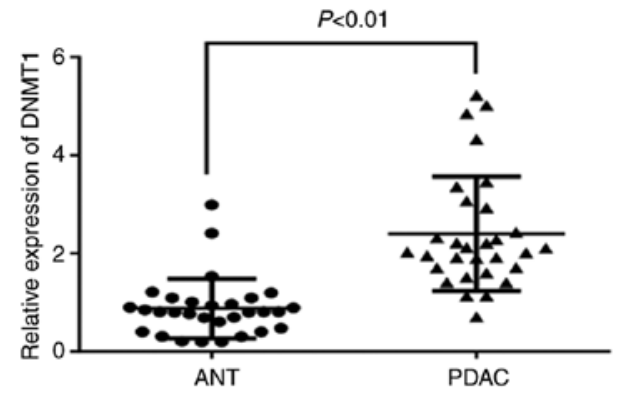

D

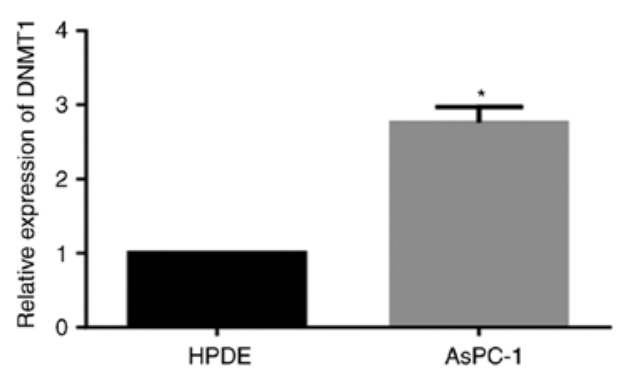

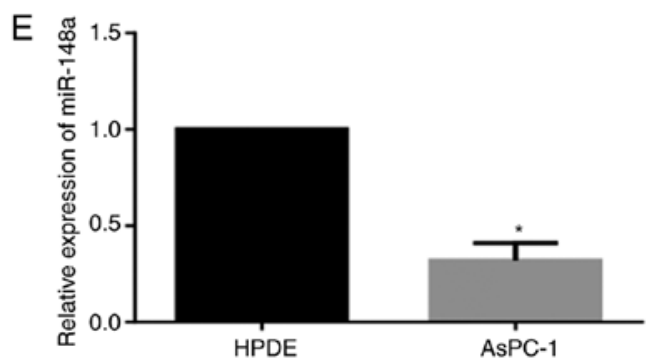

Figure 1. Association between DNMT1 and miR-148a expression in pancreatic cancer. (A) Relative miR-148a expression in ANT and PDAC specimens. (B) Relative DNMT1 expression in ANT and PDAC specimens. (C) DNMT1 expression was inversely correlated with miR-148a in PDAC tissues (Spearman's correlation analysis, $\mathrm{r}=-0.7261, \mathrm{P}<0.01$ ). (D) Relative DNMT1 expression in HPDE and AsPC-1 cells (" $\mathrm{P}<0.01$ ). (E) Relative miR-148a expression in HPDE and AsPC-1 cells ("P<0.01). ANT, adjacent non-tumorous; DNMT1, DNA methyltransferase 1; miR-148a, microRNA-148a; PDAC, pancreatic ductal adenocarcinoma.

as a potential target of miR-148a using the bioinformatics prediction tools TargetScan 7.1 (http://www.targetscan.org) and miRBase (http://www.mirbase.org/) (Fig. 4A). Therefore, a dual luciferase reporter assay was performed to validate direct binding of miR-148a to DNMT1 mRNA 3'UTR. The results indicated that miR-148a mimics significantly decreased the luciferase activity of the DNMT1 3'UTR-wt vector, but did not affect the activity of the DNMT1 3'UTR-mut vector (Fig. 4B), thus suggesting that the 3 'UTR of DNMT1 was a functional target site for miR-148a-induced silencing of DNMT1.

Restoration of miR-148a decreases the methylation levels of p16, ppENK and RASSF1A promoter regions, and reactivates their expression in AsPC-1 cells. DNMT1 is constitutively expressed in proliferating cells, and functions as a maintenance enzyme to ensure that methylation patterns are copied to daughter cells during DNA replication (28). To further investigate whether miR-148a could reactivate TSGs by targeting DNMT1, AsPC-1 cells were transfected with Lipofectamine ${ }^{\circledR}$ (blank), mimics-NC or miR-148a mimics. Subsequently, the methylation levels of three pancreatic cancer-associated TSGs, p16, ppENK and RASSF1A, were detected by MSP. As shown in Fig. 5, the methylation status of p16, ppENK and RASSF1A was positive. In addition, the basal expression levels of these three proteins were detected by western blot analysis in AsPC-1 cells. The results indicated that restoration of miR-148a altered the methylation status of p16, ppENK and RASSF1A promoter regions (p16 and ppENK, from methylated to unmethylated; RASSF1A, from methylated to partially methylated), and significantly increased the protein expression levels of p16, ppENK and RASSF1A in AsPC-1 cells (Fig. 5A and B).

miR-148a inhibits cell proliferation, migration and invasion of AsPC-1 cells. To determine the effects of miR-148a on cell proliferation, migration and invasion, AsPC-1 cells were transfected with Lipofectamine ${ }^{\circledast}$ (blank), mimics-NC or miR-148a mimics. Subsequently, the MTT assay was used to evaluate cellular proliferation, and Transwell assays were used to measure the migratory and invasive ability of AsPC- 1 cells. Compared with the two control groups, the miR-148a mimics group exhibited ascending cell proliferation at 48, 72, 96 and $120 \mathrm{~h}$ post-transfection (Fig. 6A). In addition, the migratory and invasive abilities of AsPC-1 cells were significantly reduced following miR-148a mimics transfection (Fig. 6B). These findings indicated that miR-148a overexpression may 
A
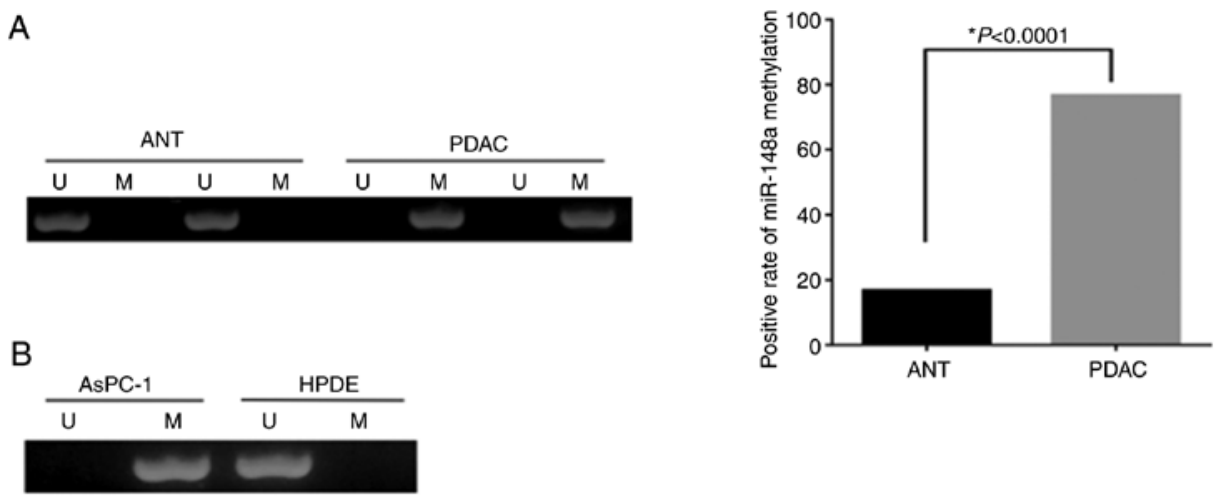

\begin{tabular}{|llllllll}
\multicolumn{4}{c}{ ANT } & \multicolumn{4}{c}{ PDAC } \\
\cline { 1 - 2 } \cline { 5 - 7 } & $M$ & $U$ & $M$ & $M$ & $U$ & $M$ \\
\hline
\end{tabular}

C
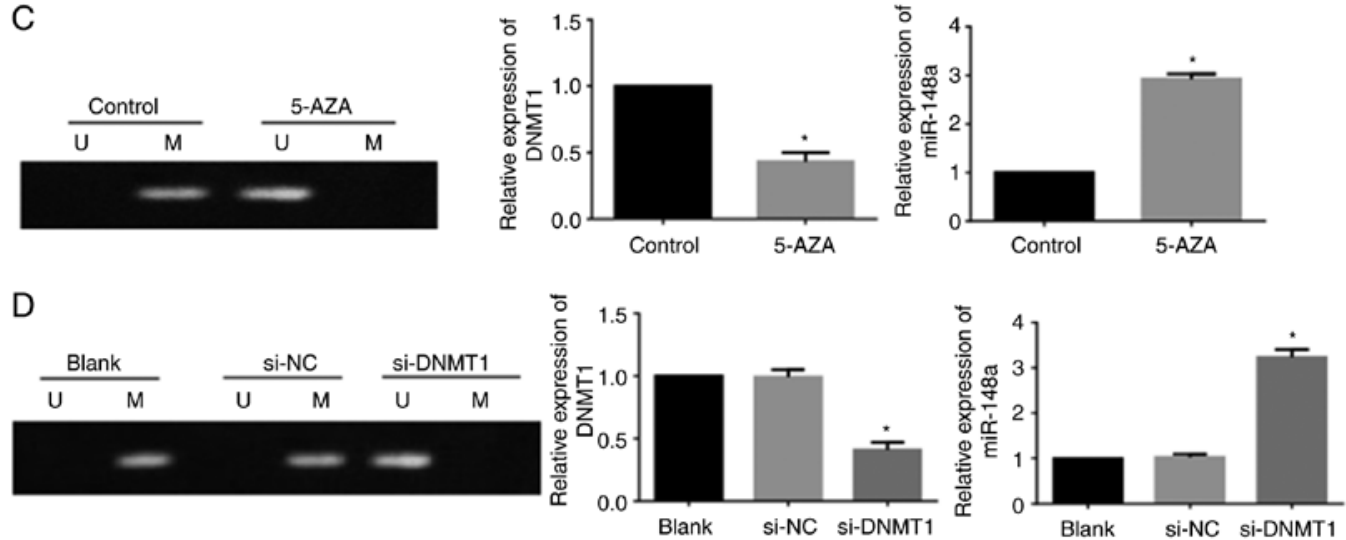

E
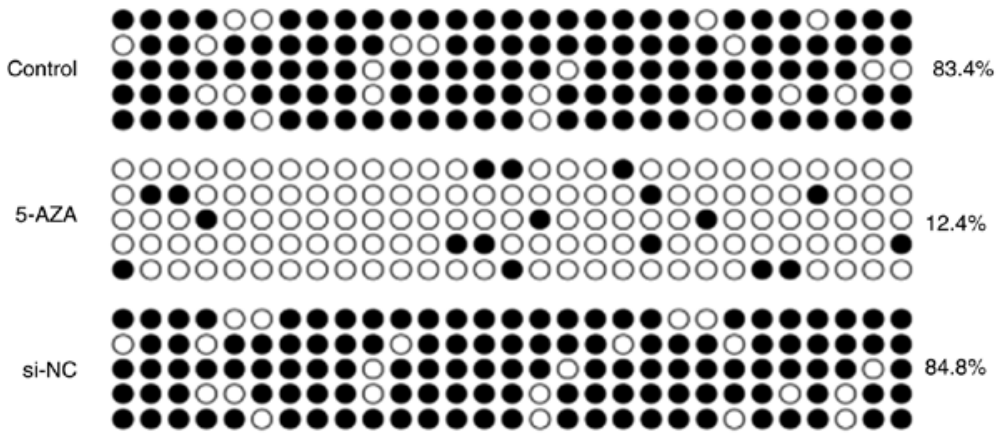

Si-DNMT

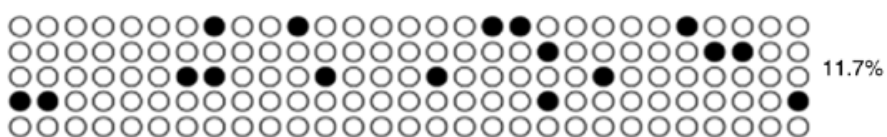

Figure 2. Methylation status of the miR-148a promoter. (A) Methylation status of the miR-148a promoter in ANT and PDAC specimens. (B) Methylation status of the miR-148a promoter in HPDE and AsPC-1 cells. (C) Effects of 5-Aza-CdR on methylation status of the miR-148a promoter, and DNMT1 and miR-148a expression ("P<0.01). (D) Effects of si-DNMT1 on methylation status of the miR-148a promoter, and DNMT1 and miR-148a expression ("P<0.01). (E) Bisulfite sequencing polymerase chain reaction analysis of $\mathrm{CpG}$ sites in the miR-148a promoter in AsPC-1 cells with or without 5-Aza-CdR treatment and si-DNMT1 transfection. Open and filled circles represent $\mathrm{U}$ and M CpG sites, respectively. Each horizontal row represents a single clone. There are 29 CpG sites. 5-AZA, 5-Aza-2'-deoxycytidine; ANT, adjacent non-tumorous; DNMT1, DNA methyltransferase 1; M, methylated; miR-148a, microRNA-148a; NC, negative control; PDAC, pancreatic ductal adenocarcinoma; si, small interfering RNA; U, unmethylated.
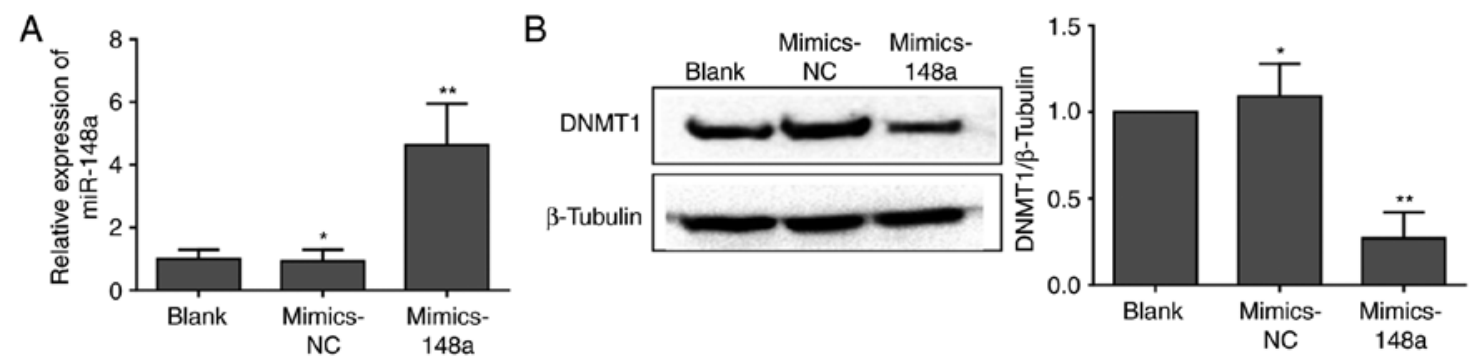

Figure 3. miR-148a suppresses DNMT1 expression in AsPC-1 cells. (A) Relative expression of miR-148a. (B) Protein expression of DNMT1. "P>0.05 compared with the blank group; ${ }^{* *} \mathrm{P}<0.01$ compared with the blank and mimics-NC groups. DNMT1, DNA methyltransferase 1; miR-148a, microRNA-148a; NC, negative control. 

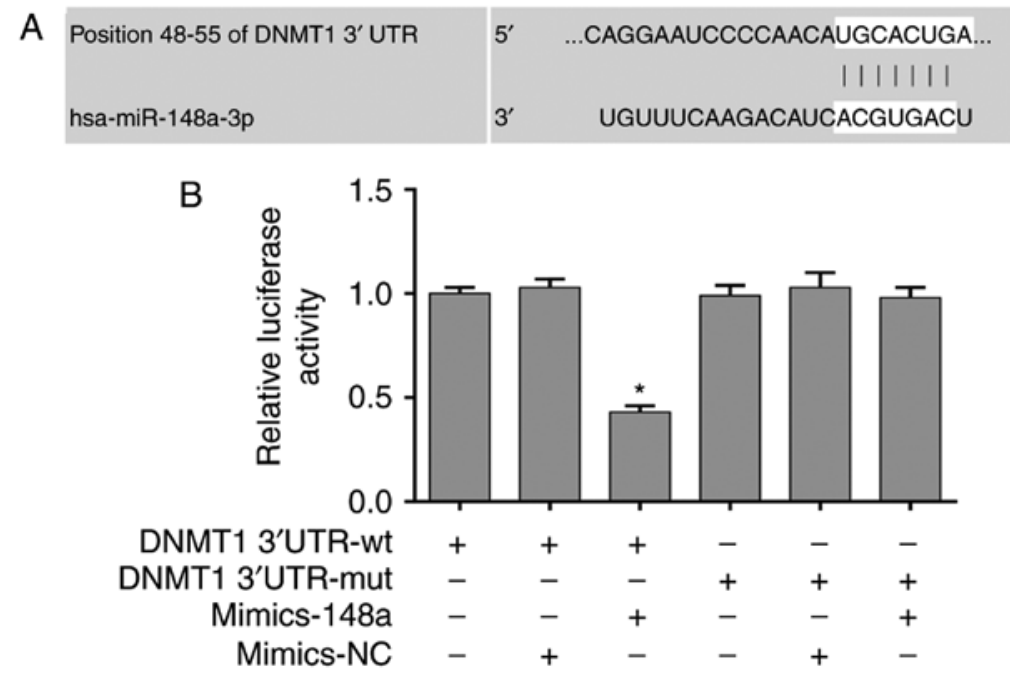

Figure 4. miR-148a directly targets DNMT1 in AsPC-1 cells. (A) Schematic representation of the predicted miR-148a binding sites in DNMT1 3'UTR (B) Luciferase activities of DNMT1 3'UTR-wt and DNMT1 3'UTR-mut constructs in AsPC-1 cells. Data are presented as the means \pm standard deviation of three independent experiments. "P<0.01, DNMT1 3'UTR-wt + mimics-148a group compared with the other five groups. 3'UTR, 3'-untranslated region; DNMT1, DNA methyltransferase 1; miR-148a, microRNA-148a; mut, mutant; NC, negative control; wt, wild type.
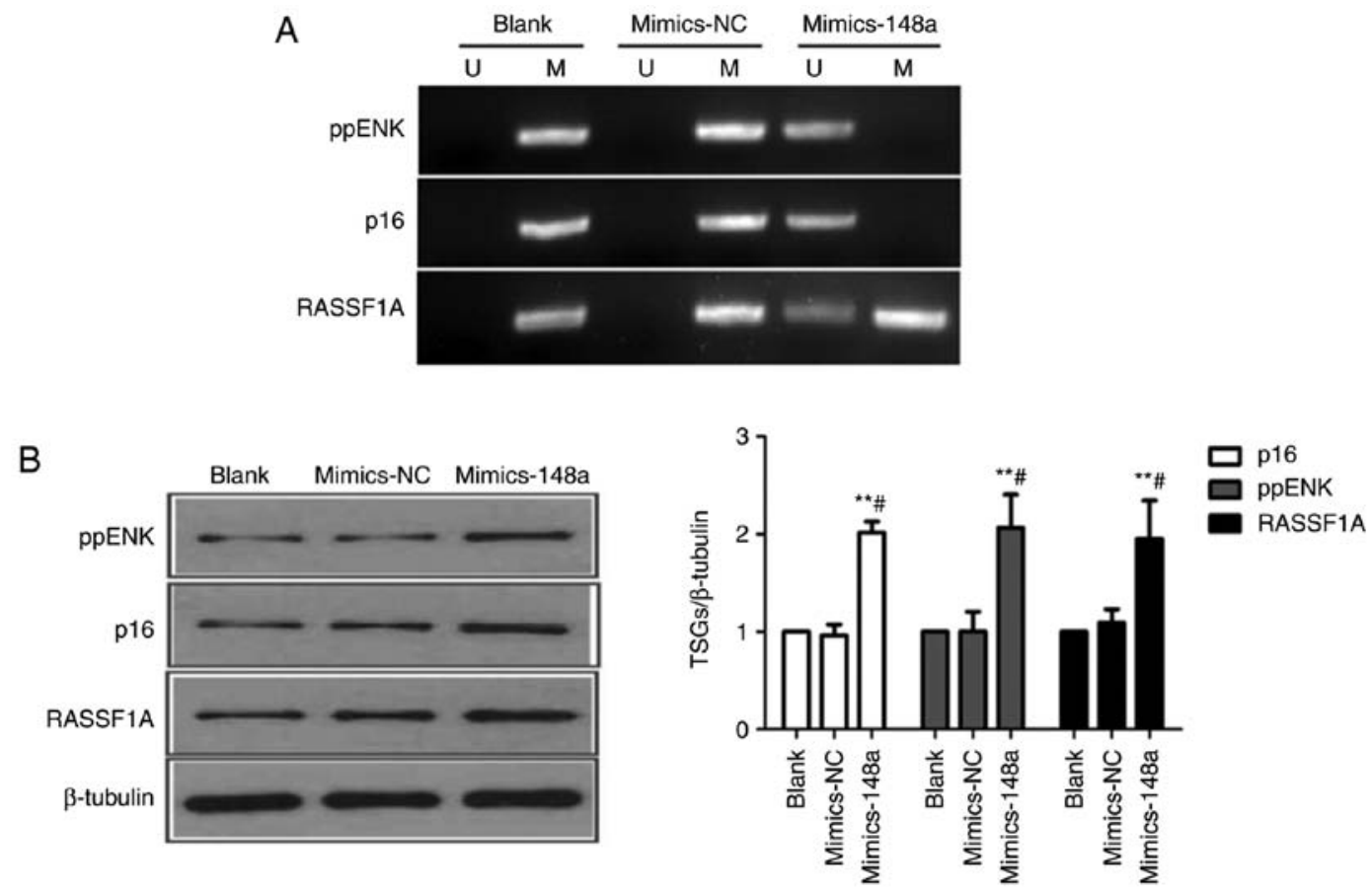

Figure 5. MicroRNA-148a reactivates p16, ppENK and RASSF1A expression in AsPC-1 cells. (A) Methylation status of p16, ppENK and RASSF1A. (B) Protein expression levels of p16, ppENK and RASSF1A. ${ }^{* *} \mathrm{P}<0.01$ compared with the blank group; ${ }^{\#} \mathrm{P}<0.01$ compared with the mimics-NC group. M, methylated; NC, negative control; ppENK, preproenkephalin; RASSF1A, Ras association domain family member 1; U, unmethylated.

inhibit cell proliferation, migration and invasion of AsPC-1 cells.

\section{Discussion}

The molecular pathogenesis of pancreatic cancer is the result of a complex multi-stage and multi-step process, which is associated with numerous genes. The inactivation of TSGs and aberrant expression of miRNAs are two important molecular mechanisms that contribute to the progression of pancreatic cancer $(29,30)$; however, their intrinsic association remains poorly understood. DNA methylation is an epigenetic mechanism that occurs following the addition of a methyl group to DNA, thereby often modifying the function of the gene and regulating gene expression. DNMT1 serves a role in maintaining methylation patterns during the DNA methylation process. The overexpression of DNMT1 has been reported to be responsible for hypermethylation and silencing of some cancer-associated miRNAs and TSGs (31-34). Furthermore, DNMT1 has been identified as the target of some miRNAs. Therefore, it was hypothesized that DNMT1 might be a functional link between miRNAs and TSGs. The present study 

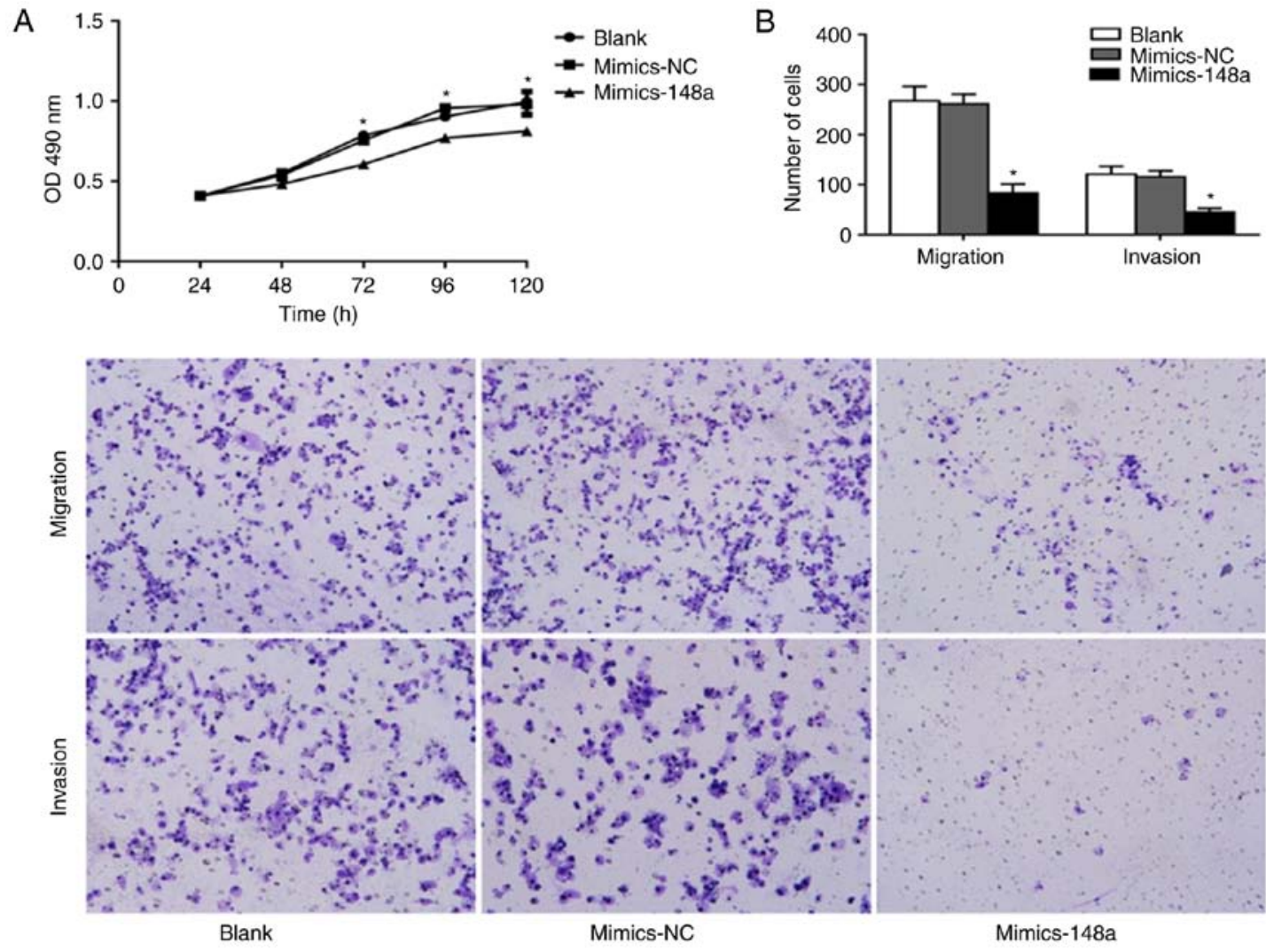

Figure 6. miR-148a inhibits proliferation, migration and invasion of AsPC-1 cells in vitro. (A) Cell proliferation was determined in AsPC-1 cells post-transfection with miR-148a mimics or mimics-NC. " $\mathrm{P}<0.05$ compared with the blank group and mimics-NC group. (B) Migration and invasion were determined in AsPC-1 cells post-transfection with miR-148a mimics or mimics-NC (magnification, $\mathrm{x} 100$ ). ${ }^{*} \mathrm{P}<0.01$ compared with the blank group and mimics-NC group. miR-148a, microRNA-148a; NC, negative control; OD, optical density.

revealed that DNMT1 was aberrantly upregulated in PDAC, and was responsible for hypermethylation of the miR-148a promoter. Furthermore, restoration of miR-148a reactivated the TSGs p16, ppENK and RASSF1A by targeting DNMT1, and inhibited cell proliferation, migration and invasion of AsPC-1 pancreatic cancer cells.

miR-148a is a member of the miR-148/152 family, which has been investigated in numerous types of cancer. In addition, its aberrant expression has a significant role in tumorigenesis and metastasis. miR-148a has been identified as a tumor suppressor miRNA in several types of cancer (5-9); however, the antitumor effects of miR-148a remain controversial in pancreatic cancer. At least four studies have revealed that re-expression of miR-148a inhibits cell proliferation, apoptosis, migration and invasion in pancreatic cancer (12-15). However, Delpu et al (35) demonstrated that miR-148a does not impact PDAC proliferation in vitro and in vivo. Our previous study revealed that upregulation of miR-148a suppresses cell migration and invasion of BxPC-3 pancreatic cancer cells (22). The present study revealed that re-expression of miR-148a in AsPC-1 pancreatic cancer cells, which was mediated by miR-148a mimics transfection, could inhibit tumor cell growth, migration and invasion. Therefore, the tumor suppressor role of miR-148a in pancreatic cancer has been validated.

Numerous TSGs are aberrantly methylated and silenced in pancreatic cancer, including p16, ppENK and RASSF1A (36). p16 is a cyclin-dependent kinase inhibitor that slows down the cell cycle by inhibiting progression from $\mathrm{G}_{1}$ phase to
S phase (37). ppENK is a neuropeptide transmitter gene that encodes Met-enkephalin, which is a topically active inhibitor of cancer that interacts with the opioid growth factor receptor (38). The protein encoded by the RASSF1A gene has a key role in mediating numerous cellular processes, including apoptosis, cell migration, cell survival and microtubule stabilization (39). The RASSF1A gene has also been revealed to arrest the cell cycle by inhibiting accumulation of cyclin D1 (40). Attri et al (41) reported that p16 expression is decreased in $80 \%(20 / 25)$ of pancreatic cancer cases, $65 \%(13 / 20)$ of which is caused by high methylation of the promoter region. Dammann et al (42) revealed that RASSF1A hypermethylation is detected in 64\% of PDAC tissues and $87.5 \%$ of eight pancreatic cancer cell lines; in addition, p16 hypermethylation is detected in $43 \%$ of PDAC tissues and $63 \%$ of eight pancreatic cancer cell lines. Fukushima et al (43) demonstrated that 93.3\% (14/15) of invasive PDAC cases exhibit ppENK methylation, whereas no methylation is detected in noncancerous pancreatic epithelium. In the present study, restoration of miR-148a altered the methylation status of p16, ppENK and RASSF1A promoter regions, and reactivated their protein expression in AsPC-1 cells. These results could explain, at least in part, the tumor suppressor effects of miR-148a. To further investigate the potential mechanism underlying the regulatory effects of miR-148a on the expression of these TSGs, the present study focused on DNMT1 due to its important role in the process of DNA methylation. Our previous study demonstrated that DNMT1-siRNA could inhibit cell growth and 
promote apoptosis of BxPC-3 pancreatic cancer cells, and its mechanisms were associated with demethylation of the TSGs p16, ppENK and RASSF1A (44). The present findings clearly suggested that DNMT1 was a direct target gene of miR-148a. This conclusion was based on numerous experimental data. Firstly, the expression of DNMT1 in PDAC tissues was negatively correlated with miR-148a. Secondly, miR-148a upregulation significantly downregulated DNMT1 expression in AsPC-1 cells. Finally, the luciferase reporter assay using the DNMT1 3'UTR-wt reporter indicated that miR-148a mimics significantly reduced luciferase activity.

The mechanism underlying aberrant downregulation of miR-148a in pancreatic cancer is another issue of concern. miR-148a has been reported to be silenced by promoter hypermethylation in gastrointestinal, hepatocellular and nasopharyngeal carcinoma (20,45-47). Hanoun et al (48) revealed that hypermethylation of the promoter region encoding miR-148a is responsible for its repression, not only in PDAC samples, but also in pancreatic intraepithelial neoplasia. Furthermore, the interplay between miR-148a and DNMT1 has been detected in PDAC, and the increased expression of miR-148a arrests UTR methylation of $\mathrm{p} 27$, giving rise to increased levels of p27, which is a cyclin-dependent kinase inhibitor that possesses tumor suppressor activity (12). The present results demonstrated that DNMT1 was overexpressed in PDAC tissues and AsPC-1 cells, which was accompanied by hypermethylation of the miR-148a promoter. In AsPC-1 cells treated with 5-Aza-CdR or DNMT1-siRNA, DNMT1 was downregulated, miR-148a expression was significantly increased, and the miR-148a promoter was demethylated. Furthermore, the results of BSP indicated that the methylated $\mathrm{CpG}$ sites of miR-148a were significantly decreased in 5-Aza-CdR-treated or DNMT1-siRNA-transfected AsPC-1 cells. Therefore, it may be concluded that overexpression of DNMT1 leads to the hypermethylation and silencing of miR-148a in pancreatic cancer.

In conclusion, the present study demonstrated that DNMT1 was aberrantly upregulated in pancreatic cancer, and its overexpression was responsible for hypermethylation of the miR-148a promoter. Furthermore, restoration of miR-148a reactivated the TSGs p16, ppENK and RASSF1A by targeting DNMT1. These results indicated that an interaction exists between miR-148a and DNMT1 in pancreatic cancer. Notably, overexpression of miR-148a significantly inhibited cell proliferation, migration and invasion in pancreatic cancer cells These results suggested the existence of a miR-148a-DNMT1 regulatory circuit and indicated that miR-148a may be a potential therapeutic target in pancreatic cancer.

\section{Acknowledgements}

Not applicable.

\section{Funding}

The present study was supported by the National Natural Science Foundation of China (grant no. 81660401), the Natural Science Foundation of Jiangxi Province (grant no. 20161BAB205242) and the Scientific Research Foundation of the Education Office Jiangxi Province (grant no. GJJ14018).

\section{Availability of data and materials}

All data generated or analyzed during this study are included in this published article.

\section{Authors' contributions}

WX and YL designed the study. LH and GS wrote the manuscript, collected clinical information and performed statistical analyses. LH, GS, LP, ZW and WX performed the experiments. HX assisted with the dual-luciferase reporter assays. YT conducted the pathological diagnosis of the pancreatic tissues and assisted with the Transwell assays. All authors read and approved the manuscript, and agree to be accountable for all aspects of the research in ensuring that the accuracy or integrity of any part of the work are appropriately investigated and resolved.

\section{Ethics approval and consent to participate}

Written informed consent was provided by all participants and volunteers prior to recruitment. The present study was approved by the Ethics Committee of the First Affiliated Hospital of Nanchang University.

\section{Patient consent for publication}

Not applicable.

\section{Competing interests}

The authors declare that they have no competing interests.

\section{References}

1. Siegel RL, Miller KD and Jemal A: Cancer statistics, 2018. CA Cancer J Clin 68: 7-30, 2018.

2. Rahib L, Smith BD, Aizenberg R, Rosenzweig AB, Fleshman JM and Matrisian LM: Projecting cancer incidence and deaths to 2030: The unexpected burden of thyroid, liver, and pancreas cancers in the United States. Cancer Res 74: 2913-2921, 2014.

3. Chen W, Zheng R, Baade PD, Zhang S, Zeng H, Bray F, Jemal A, $\mathrm{Yu}$ XQ and He J: Cancer statistics in China, 2015. CA Cancer J Clin 66: 115-132, 2016.

4. Chan SH and Wang LH: Regulation of cancer metastasis by microRNAs. J Biomed Sci 22: 9, 2015.

5. Xu Q, Jiang Y, Yin Y, Li Q, He J, Jing Y, Qi YT, Xu Q, Li W, $\mathrm{Lu} \mathrm{B}$, et al: A regulatory circuit of miR-148a/152 and DNMT1 in modulating cell transformation and tumor angiogenesis through IGF-IR and IRS1. J Mol Cell Biol 5: 3-13, 2013.

6. Zhang H, Li Y, Huang Q, Ren X, Hu H, Sheng H and Lai M: MiR-148a promotes apoptosis by targeting Bcl-2 in colorectal cancer. Cell Death Differ 18: 1702-1710, 2011.

7. Sakamoto N, Naito Y, Oue N, Sentani K, Uraoka N, Zarni Oo H, Yanagihara K, Aoyagi K, Sasaki H and Yasui W: MicroRNA-148a is downregulated in gastric cancer, targets MMP7, and indicates tumor invasiveness and poor prognosis. Cancer Sci 105: 236-243, 2014.

8. Braconi C, Huang N and Patel T: MicroRNA-dependent regulation of DNA methyltransferase-1 and tumor suppressor gene expression by interleukin-6 in human malignant cholangiocytes. Hepatology 51: 881-890, 2010.

9. Heo MJ, Kim YM, Koo JH, Yang YM, An J, Lee SK, Lee SJ, Kim KM, Park JW and Kim SG: microRNA-148a dysregulation discriminates poor prognosis of hepatocellular carcinoma in association with USP4 overexpression. Oncotarget 5: 2792-2806, 2014. 
10. Bloomston M, Frankel WL, Petrocca F, Volinia S, Alder H, Hagan JP, Liu CG, Bhatt D, Taccioli C and Croce CM: MicroRNA expression patterns to differentiate pancreatic adenocarcinoma from normal pancreas and chronic pancreatitis. JAMA 297: 1901-1908, 2007.

11. Szafranska AE, Davison TS, John J, Cannon T, Sipos B, Maghnouj A, Labourier E and Haln SA: MicroRNA expression alterations are linked to tumorigenesis and non-neoplastic processes in pancreatic ductal adenocarcinoma. Oncogene 26: 4442-4452, 2007.

12. Zhan Q, Fang Y, Deng X, Chen H, Jin J, Lu X, Peng C, Li H and Shen B: The interplay between miR-148a and DNMT1 might be exploited for pancreatic cancer therapy. Cancer Invest 33: 267-275, 2015.

13. Zhang R, Li M, Zang W, Chen X, Wang Y, Li P, Du Y, Zhao G and $\mathrm{Li} \mathrm{L}: \mathrm{MiR}-148$ a regulates the growth and apoptosis in pancreatic cancer by targeting CCKBR and Bcl-2. Tumour Biol 35: 837-44, 2014.

14. Liffers ST, Munding JB, Vogt M, Kuhlmann JD, Verdoodt B, Nambiar S, Maghnouj A, Mimohammadsadegh A, Hahn SA and Tannapfel A: MicroRNA-148a is down-regulated in human pancreatic ductal adenocarcinomas and regulates cell survival by targeting CDC25B. Lab Invest 91: 1472-1479, 2011.

15. Feng H, Wang Y, Su J, Liang H, Zhang CY, Chen X and Yao W: MicroRNA-148a suppresses the proliferation and migration of pancreatic cancer cells by down-regulating ErbB3. Pancreas 45: 1263-1271, 2016.

16. Lopez-Serra P and Esteller M: DNA methylation-associated silencing of tumor-suppressor microRNAs in cancer. Oncogene 31: 1609-1622, 2012.

17. Xie K, Liu J, Chen J, Dong J, Ma H, Liu Y and Hu Z: Methylation-associated silencing of microRNA-34b in hepatocellular carcinoma cancer. Gene 543: 101-107, 2014.

18. Peng DF, Kanai Y, Sawada M, Ushijima S, Hiraoka N, Kosuge T and Hirohashi S: Increased DNA methyltransferase 1 (DNMT1) protein expression in precancerous conditions and ductal carcinomas of the pancreas. Cancer Sci 96: 403-408, 2005.

19. Li A, Omura N, Hong SM and Goggins M: Pancreatic cancer DNMT1 expression and sensitivity to DNMT1 inhibitors. Cancer Biol Ther 9: 321-329, 2010.

20. Zhu A, Xia J, Zuo J, Jin S, Zhou H, Yao L, Huang H and Han Z: MicroRNA-148a is silenced by hypermethylation and interacts with DNA methyltransferase 1 in gastric cancer. Med Oncol 29: 2701-2709, 2012.

21. Long XR, He Y,Huang C and Li J: MicroRNA-148a is silenced by hypermethylation and interacts with DNA methyltransferase 1 in hepatocellular carcinogenesis. Int J Oncol 44: 1915-1922, 2014.

22. Peng L, Liu Z, Xiao J, Tu Y, Wan Z, Xiong H, Li Y and Xiao W: MicroRNA-148a suppresses epithelial-mesenchymal transition and invasion of pancreatic cancer cells by targeting Wnt10b and inhibiting the Wnt/ $\beta$-catenin signaling pathway. Oncol Rep 38 301-308, 2017.

23. Livak KJ and Schmittgen TD: Analysis of relative gene expression data using real-time quantitative PCR and the $2^{-{ }^{-\Delta} C_{\mathrm{T}}}$ method. Methods 25: 402-408, 2001.

24. Sanger F, Nicklen $S$ and Coulson AR: DNA sequencing with chain-terminating inhibitors. Proc Natl Acad Sci USA 74:5463-5467, 1977.

25. Kumaki Y, Oda M and Okano M: QUMA: Quantification tool for methylation analysis. Necleic Acids Res 36: W170-W175, 2008.

26. Bock C, Reither S, Mikeska T, Paulsen M, Walter J and Lengauer T: BiQ Analyzer: Visualization and quality control for DNA methylation data from bisulfite sequencing. Bioinformatics 21: 4067-4068, 2005.

27. Lee J, Shin MK, Ryu DK, Kim S and Ryu WS: Insertion and deletion mutagenesis by overlap extension PCR. Methods Mol Biol 634:137-146, 2010.

28. Bestor TH: The DNA methyltransferases of mammals. Hum Mol Genet 9: 2395-2402, 2000.

29. Cowan RW and Maitra A: Genetic progression of pancreatic cancer. Cancer J 20: 80-84, 2014.

30. Yonemori K, Kurahara H, Maemura K and Natsugoe S: MicroRNA in pancreatic cancer. J Hum Genet 62: 33-40, 2017.
31. Yang L, Luo P, Song Q and Fei X: DNMT1/miR-200a/GOLM1 signaling pathway regulates lung adenocarcinoma cells proliferation. Biomed Pharmacother 99: 839-847, 2018.

32. Ning X, Shi Z, Liu X, Zhang A, Han L, Jiang K, Kang C and Zhang Q: DNMT1 and EZH2 mediated methylation silences the microRNA-200b/a/429 gene and promotes tumor progression. Cancer Lett 59: 198-205, 2015.

33. Peng DF, Kanai Y, Sawada M, Ushijima S, Hiraoka N, Kitazawa S and Hirohashi S: DNA methylation of multiple tumor-related genes in association with overexpression of DNA methyltransferase 1 (DNMT1) during multistage carcinogenesis of the pancreas. Carcinogenesis 27: 1160-1168, 2006.

34. Liu B, Song J, Luan J, Sun X, Bai J, Wang H, Li A, Zhang L, Feng $\mathrm{X}$ and $\mathrm{Du} \mathrm{Z}$ : Promoter methylation status of tumor suppressor genes and inhibition of expression of DNA methyltransferase 1 in non-small cell lung cancer. Exp Biol Med 241: 1531-1539, 2016.

35. Delpu Y, Lulka H, Sicard F, Saint-Laurent N, Lopez F, Hanoun N, Buscail L, Cordelier P and Torrisani J: The rescue of miR-148a expression in pancreatic cancer: An inappropriate therapeutic tool. PLoS One 8: e55513, 2013.

36. Pan FP, Zhou HK, Bu HQ, Chen ZQ, Zhang H, Xu LP, Tang J, Yu QJ, Chu YQ, Pan J, et al: Emodin enhances the demethylation by 5 -AZa-CdR of pancreatic cancer tumor-suppressor genes P16, RASSF1A and ppENK. Oncol Rep 35: 1941-1949, 2016.

37. Witkiewicz AK, Knudsen KE, Dicker AP and Knudsen ES: The meaning of p16 ink4a expression in tumors: Functional significance, clinical associations and future developments. Cell Cycle 10: 2497-2503, 2011

38. Yang L, Yang H, Li J, Hao J and Qian J: ppENK gene methylation status in the development of pancreatic carcinoma. Gastroenterol Res Pract 2013:130927, 2013.

39. Vos MD, Martinez A, Elam C, Dallol A, Taylor BJ, Latif F and Clark GJ: A role for the RASSF1A tumor suppressor in the regulation of tubulin polymerization and genomic stability. Cancer Res 64: 4244-4250, 2004

40. Shivakumar L, Minna J, Sakamaki T, Pestell R and White MA: The RASSF1A tumor suppressor blocks cell cycle progression and inhibits cyclin D1 accumulation. Mol Cell Biol 22: 4309-4318, 2002.

41. Attri J, Srinivasan R, Majumdar S, Radotra BD and Wig J: Alterations of tumor suppressor gene p16INK4a in pancreatic ductal carcinoma. BMC Gastroenterol 5: 22, 2005.

42. Dammann R, Schagdarsurengin U, Liu L, Otto N, Gimm O, Dralle H, Boehm BO, Pfeifer GP and Hoang-Vu C: Frequent RASSF1A promoter hypermethylation and K-ras mutations in pancreatic carcinoma. Oncogene 22: 3806-3812, 2003.

43. Fukushima N, Sato N, Ueki T, Rosty C, Walter KM, Wilentz RE, Yeo CJ, Hruban RH and Goggins M: Aberrant methylation of preproenkephalin and p16 genes in pancreatic intraepithelial neoplasia and pancreatic ductal adenocarcinoma. Am J Pathol 160: 1573-1581, 2002.

44. Xiao WD, Li Y, Li XM, Cai J, Zeng LS and Hu W: RNA interference-mediated silencing of the DNMT1 gene inhibits cell proliferation in human pancreatic carcinoma cell line BxPC-3. Shijie Huaren Xiaohua Zazhi 19: 3397-3401, 2011 (In Chinese).

45. Sun J, Song Y, Wang Z, Wang G, Gao P, Chen X, Gao Z and $\mathrm{Xu} \mathrm{H}$ : Clinical significance of promoter region hypermethylation of microRNA-148a in gastrointestinal cancers. Onco Targets Ther 7: 853-863, 2014

46. Long XR, He Y, Huang C and Li J: MicroRNA-148a is silenced by hypermethylation and interacts with DNA methyltransferase in hepatocellular carcinogenesis. Int J Oncol 44: 1915-1922, 2014.

47. Li HP, Huang HY, Lai YR, Huang JX, Chang KP, Hsueh C and Chang YS: Silencing of miRNA-148a by hypermethylation activates the integrin-mediated signaling pathway in nasopharyngeal carcinoma. Oncotarget 5: 7610-7624, 2014.

48. Hanoun N, Delpu Y, Suriawinata AA, Bournet B, Bureau C, Selves J, Tsongalis GJ, Dufresne M, Buscail L, Cordelier P and Torrisani J: The silencing of microRNA 148 a production by DNA hypermethylation is an early event in pancreatic carcinogenesis. Clin Chem 56: 1107-1118, 2010. 